\title{
Trapping an Oxidized and Protonated Intermediate of the [FeFe]- Hydrogenase Cofactor under Mildly Reducing Conditions
}

Moritz Senger ${ }^{a *}$, Jifu Duan $^{\mathrm{b}}$, Mariia Pavliuk ${ }^{\mathrm{a}}$, Ulf-Peter Apfel ${ }^{\mathrm{c}, \mathrm{d}}$, Michael Haumann ${ }^{\mathrm{e}}$, and Sven T. Stripp $^{\text {f* }}$

a) Department of Chemistry, Physical Chemistry, Uppsala University, 75120 Uppsala, Sweden

b) Faculty of Biology and Biotechnology, Photobiotechnology, Ruhr-Universität Bochum, 44801 Bochum, Germany

c) Faculty of Chemistry and Biochemistry, Small Molecule Activation, Ruhr-Universität Bochum, 44801 Bochum, Germany

d) Fraunhofer UMSICHT, Electrosynthesis, 46047 Oberhausen, Germany

e) Department of Physics, Biophysics of Metalloenzymes, Freie Universität Berlin, 14195 Berlin, Germany

f) Department of Physics, Experimental Molecular Biophysics, Freie Universität Berlin, 14195

Berlin, Germany

*To whom correspondence should be addressed

moritz.senger@,kemi.uu.se and sven.stripp@,fu-berlin.de

\begin{abstract}
The H-cluster is the catalytic cofactor of [FeFe]-hydrogenase, a metalloenzyme that catalyzes the production of hydrogen gas $\left(\mathrm{H}_{2}\right)$. The $\mathrm{H}$-cluster carries two cyanide and three carbon monoxide ligands, making it an excellent target for IR spectroscopy. In previous work, we identified an oxidized and protonated H-cluster species, whose IR signature differs from the oxidized resting state (Hox) by a small but distinct shift to higher frequencies. This 'blue shift' was explained by a protonation at the [4Fe-4S] sub-complex of the H-cluster. The novel species, denoted HoxH, was preferentially accumulated at low $\mathrm{pH}$ and in the presence of the exogenous reductant sodium dithionite (NaDT). When HoxH was reacted with $\mathrm{H}_{2}$, the hydride state (Hhyd) was formed, a key intermediate of $[\mathrm{FeFe}]$-hydrogenase turnover. A recent publication revisited our protocol for the accumulation of HoxH in wild-type [FeFe]-hydrogenase, concluding that inhibition by NaDT decay products rather than cofactor protonation causes the spectroscopic 'blue shift'. Here, we demonstrate that HoxH formation does not require the presence of $\mathrm{NaDT}$ (or its decay products), but accumulates also with the milder reductants tris(2-carboxyethyl)phosphine, dithiothreitol, or ascorbic acid, in particular at low $\mathrm{pH}$. Our data consistently suggest that HoxH is accumulated when deprotonation of the H-cluster is impaired, thereby preventing the regain of the oxidized resting state Hox in the catalytic cycle.
\end{abstract}




\section{INTRODUCTION}

Hydrogenases are gas-processing metalloenzymes that catalyze hydrogen turnover $\left(2 \mathrm{H}^{+}+2 e^{-} \rightleftharpoons\right.$ $\mathrm{H}_{2}$ ) in archaea, bacteria, and certain algae. ${ }^{[1]}$ Among the three different classes, [FeFe]hydrogenases show the highest turnover frequencies with an estimated proton reduction rate exceeding $20,000 \mathrm{H}_{2} / \mathrm{s} .{ }^{[2-4]}$ Notably, this reaction occurs close to the $\mathrm{H}_{2} / \mathrm{H}^{+}$standard potential of $420 \mathrm{mV}$ vs. SHE ${ }^{[5]}$, making [FeFe]-hydrogenase the most efficient biological catalysts for $\mathrm{H}_{2}$ turnover and inspiring bioinorganic model system. ${ }^{[6-8]}$

The active site cofactor of $[\mathrm{FeFe}]$-hydrogenase is comprised of a $[4 \mathrm{Fe}-4 \mathrm{~S}]$ cluster $\left([4 \mathrm{Fe}]_{\mathrm{H}}\right)$ covalently attached via a cysteine sidechain to a unique diiron site, $[2 \mathrm{Fe}]_{\mathrm{H}}$. The latter is coordinated with two cyanide $\left(\mathrm{CN}^{-}\right)$, three carbon monoxide (CO), and an 'azadithiolate' ligand (ADT). Together, $[4 \mathrm{Fe}]_{\mathrm{H}}$ and $[2 \mathrm{Fe}]_{\mathrm{H}}$ are referred to as 'H-cluster' (Fig. 1). In the oxidized resting state, Hox, the iron ion distal to the $[4 \mathrm{Fe}]_{\mathrm{H}}$ cluster $\left(\mathrm{Fe}_{\mathrm{d}}\right)$ shows an apical vacancy. ${ }^{[9]} \mathrm{Here}$, protons and $\mathrm{H}_{2}$ may bind during catalytic turnover, a $\mathrm{CO}$ molecule may bind to form a reversibly inhibited state $(\mathbf{H o x}-\mathbf{C O})^{[10]}$, and $\mathrm{O}_{2}$ may interact in more deleterious reactions. ${ }^{[11]}$

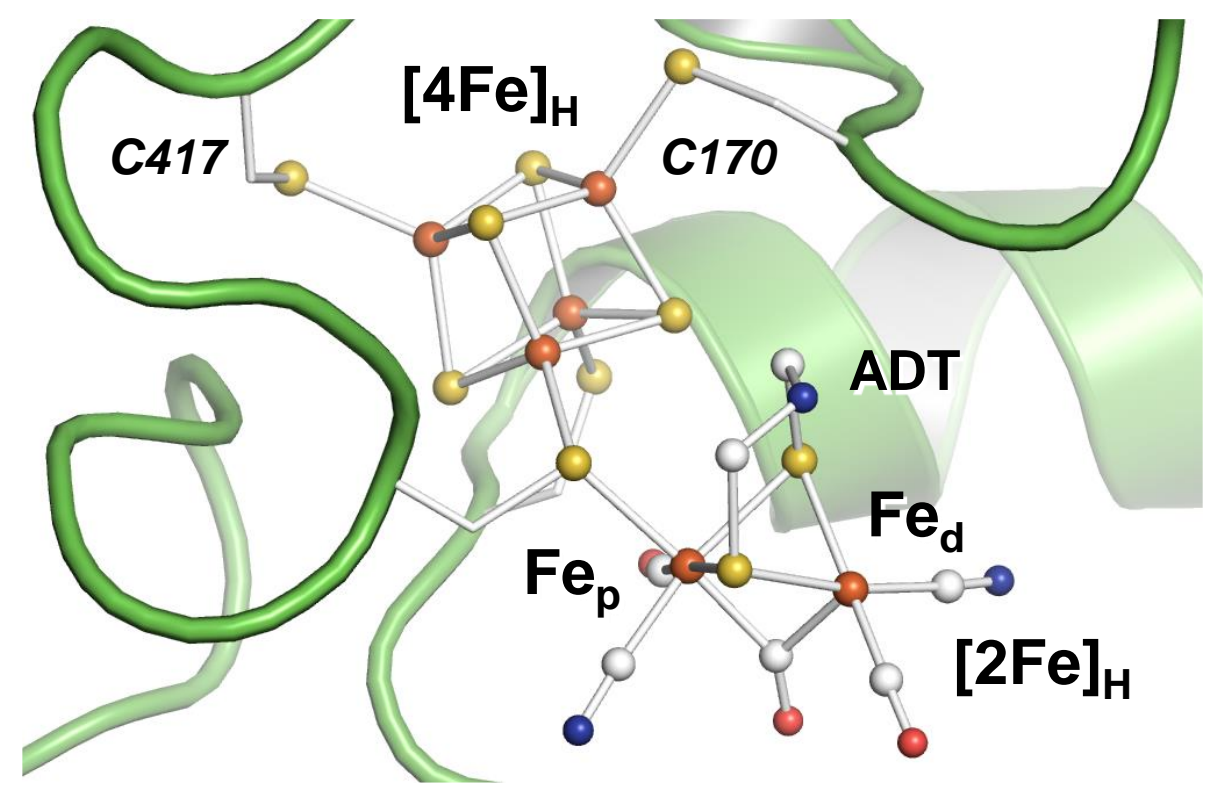

Figure 1. The catalytic cofactor of $[\mathrm{FeFe}]$-hydrogenase. The distal iron ion of the $[2 \mathrm{Fe}]_{\mathrm{H}}$ cluster $\left(\mathrm{Fe}_{\mathrm{d}}\right)$ shows an apical vacancy where $\mathrm{H}_{2}$ binds during catalytic turnover and protons are exchanged via the adt ligand ( $\mathrm{Fe}_{\mathrm{p}}$, proximal iron ion). At the $[4 \mathrm{Fe}]_{\mathrm{H}}$ cluster, cysteine $\mathrm{C} 417$ and/or $\mathrm{C} 170$ ( $C r$ HydA1 numbering) may accept a proton in certain redox states. Drawn after PDB ID 4XDC. ${ }^{[12]}$ 
Both Hox and Hox-CO are defined by an oxidized [4Fe-4S] cluster $\left([4 \mathrm{Fe}]_{\mathrm{H}^{2+}}\right)$ and a mixed-valence diiron site $\left(\left[\mathrm{Fe}_{\mathrm{p}}(\mathrm{II}) \mathrm{Fe}_{\mathrm{d}}(\mathrm{I})\right]\right) \cdot{ }^{[13]}$ Upon reduction of the $[4 \mathrm{Fe}-4 \mathrm{~S}]$ cluster $\left([4 \mathrm{Fe}]_{\mathrm{H}}{ }^{1+}\right)$, Hred' is formed. At variance with Hox, this state is diamagnetic and characterized by a small shift to lower frequencies of the $\mathrm{CO} / \mathrm{CN}^{-}$absorbance bands in the IR spectrum. ${ }^{[14]}$ Reduction of the diiron site leads to Hred, which differs from Hox by a stronger effect on the IR signature, additionally complicated by changes in cofactor geometry at ambient temperature. ${ }^{[15]}$ With respect to Hred, formation of the two-electron reduced state Hsred causes a small IR shift similar to the difference between Hox and Hred' ${ }^{[16]}$

A key intermediate in the catalytic cycle is the so-called hydride state (Hhyd), characterized by a $[4 \mathrm{Fe}]_{\mathrm{H}}{ }^{1+},\left[\mathrm{Fe}_{\mathrm{p}}(\mathrm{II}) \mathrm{Fe}_{\mathrm{d}}(\mathrm{II})\right]$ configuration with an apical hydride ligand at $\mathrm{Fe}_{\mathrm{d}} \cdot{ }^{[17-21]}$ In previous work, we established a protocol to accumulate Hhyd in wild-type [FeFe]-hydrogenase. For this, the enzyme is exposed to acidic and reducing conditions, i.e., $\mathrm{pH} 4$ and $2 \mathrm{mM}$ sodium dithionite $\left(\mathrm{Na}_{2} \mathrm{~S}_{2} \mathrm{O}_{4}\right.$ or NaDT) ${ }^{[20]}$ Before the reaction with $\mathrm{H}_{2}$ favors accumulation of Hhyd, such samples adopt an oxidized species that differs from Hox by a distinct IR 'blue shift', i.e., all cofactor bands shift to higher frequencies. ${ }^{[14]}$ Moreover, the $g_{2}$ tensors of the rhombic EPR signal of Hox and HoxH are slightly different (2.044 and 2.048, respectively). ${ }^{[6]}$ Both techniques exploit the diiron site to report on changes in the second coordination sphere of the H-cluster. Based on experimental and computational evidence, we found that protonation at a cysteine ligand of the $[4 \mathrm{Fe}]_{\mathrm{H}}$ cluster (C417 and/or C170 in Fig. 1) accounts best for the 'blue shift', prompting us to suggest a novel Hcluster species, HoxH. ${ }^{[14]}$ Similar protonation processes may occur in Hred' and Hhyd ${ }^{[22-24]}$ although this view has been debated. ${ }^{[25]}$

Recently, Martini et al. revisited our protocol for the accumulation of $\mathbf{H o x H}$ in the [FeFe]hydrogenase from $C$. reinhardtii (CrHydA1). ${ }^{[26]}$ The authors were concerned about the limited stability of $\mathrm{NaDT}$ in solution. Addition of $\mathrm{Na}_{2} \mathrm{SO}_{3}$ - a product of oxidative $\mathrm{NaDT}$ decay - indeed induced the 'blue shift' reaction, which led to the conclusion that HoxH represents a dithioniteinhibited species ('Hox-DTi'). In the present study, we demonstrate that the formation of HoxH readily occurs in the presence of various mild reductants and does not require the presence of $\mathrm{NaDT}$ (or its decay products). 


\section{RESULTS AND DISCUSSION}

$C r$ HydA1 was synthesized and activated as reported earlier. ${ }^{[27]}$ The holoenzyme was carefully washed to remove any traces of $\mathrm{NaDT}$ (see Supporting Information for details). After concentration, the protein samples comprised $\sim 1 \mathrm{mM} \mathrm{CrHydA1} \mathrm{in} 10 \mathrm{mM}$ Tris/HCl buffer (pH 8). To probe the Hox to HoxH transition with alternative reductants, we prepared solutions of $20 \mathrm{mM}$ tris(2-carboxyethyl)phosphine (TCEP), dithiothreitol (DTT), or ascorbic acid in $200 \mathrm{mM}$ 'mixed buffer' (PIPPS, MES, and Tris) adjusted to $\mathrm{pH} 4$ (Fig. S1). The as-isolated protein sample was diluted 1:1 with 'mixed buffer' containing TCEP, DTT, ascorbic acid, or no reductant. The later samples were prepared at $\mathrm{pH} 4$ or $\mathrm{pH} 8$.

These five samples were characterized by in situ ATR FTIR spectroscopy under a stream of 'wet' $\mathrm{N}_{2}$ aerosol or 'dry' $\mathrm{N}_{2}$ gas (see Supporting Information for details on the preparation of protein films). ${ }^{[28]}$ After $1-2 \mathrm{~h}$ incubation with $\mathrm{N}_{2}$ in the preparatory stage of the experiment, all samples displayed a comparable composition of H-cluster states ( $\sim 90 \% \mathbf{H o x},<10 \%$ Hred, and a very small fraction of Hox-CO, see Fig. S2). Hred' was exclusively observed in samples at pH 8, as acidic

pH values suppress Hred' (Fig. S3). ${ }^{[16]}$ While [FeFe]-hydrogenases prepared at pH 4 have been shown to adopt HoxH as main oxidized resting state in the presence of $\mathrm{NaDT}^{[20-22]}$, we now found that HoxH is not observed at pH 4 when $C r H y d A 1$ was mixed with TCEP, DTT, ascorbic acid, or no reductant (Fig. S2A).

The accumulation of HoxH is directly related to the $\mathrm{pH}$ value and the NaDT concentration but also affected by the presence of redox mediators and the protein concentration. ${ }^{[14,22]}$ The latter observation was rationalized by intermolecular electron transfer in the densely packed sample film. ${ }^{[14]}$ The protein concentration can be increased in situ by diminishing the water content in the sample film, switching from a 'wet' to a 'dry' $\mathrm{N}_{2}$ gas stream - a unique feature of our ATR FTIR setup. ${ }^{[28]}$ Fig. 2A depicts the global IR spectral changes upon partial dehydration of the CrHydA1/TCEP protein film and the concomitant accumulation of HoxH over Hox in the frequency regime of the H-cluster (lower panel). Fig. 3A shows the respective changes in the time domain. Starting at time point $\mathrm{t}_{0}$, the hydration level is tracked via the intensity of the symmetric $\mathrm{OH}$ stretching band of liquid water $\left(v_{1}\right)$ at $3360 \mathrm{~cm}^{-1}$. The associated changes in protein concentration are followed via the amide II band of the protein backbone at $1540 \mathrm{~cm}^{-1}$. The water content was decreased by up to $50 \%$ (i.e., the $v_{1}$ absorbance changes from $\sim 0.45$ to $\sim 0.22$ ). Sample 
rehydration after time point $t_{2}$ led to a complete reversion of the observed changes. Fig. 2B shows how the initial increase of Hox between time points $\mathrm{t}_{0}$ and $\mathrm{t}_{1}(\Delta \mathrm{t}=2 \mathrm{~min})$ is followed by a slower Hox to HoxH conversion. Afterwards, rehydration shifts the equilibrium immediately back to Hox without notable loss of cofactor integrity, highlighting the reversibility of the state conversion.

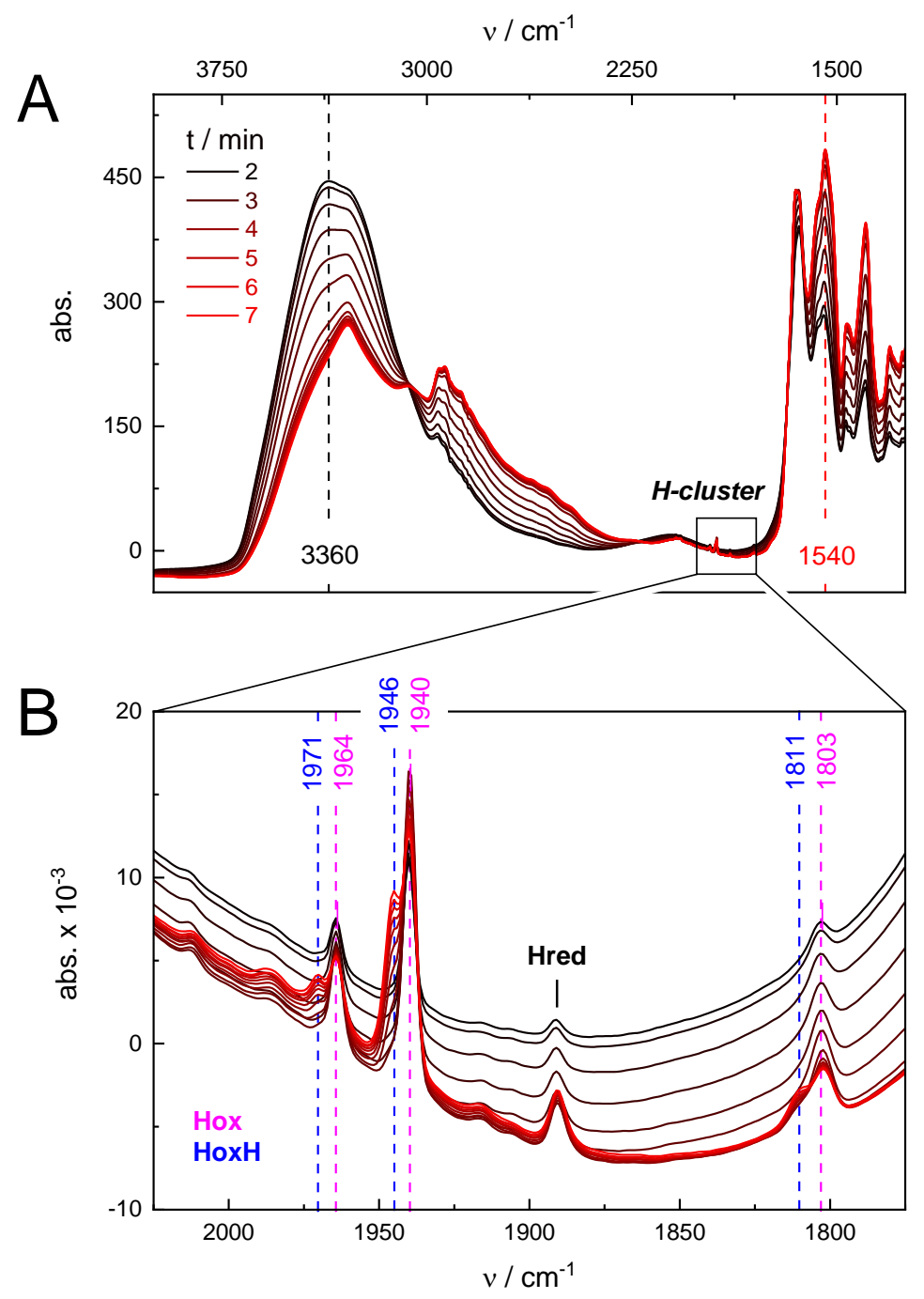

Figure 2. Accumulation of HoxH upon dehydration. ATR FTIR spectra of a $\mathrm{CrHydA1}$ protein film at $\mathrm{pH} 4$ with $10 \mathrm{mM}$ TCEP. (A) From black to red, the spectral changes upon dehydration of the protein film are shown. Bands at $3360 \mathrm{~cm}^{-1}$ and $1540 \mathrm{~cm}^{-1}$ are assigned to liquid water $\left(v_{1}\right)$ and protein (amide II), respectively. (B) The band changes in the $\mathrm{CO}$ frequency regime of the $\mathrm{H}$-cluster are assigned to Hox and HoxH (magenta and blue labels, respectively). A residual fraction of Hred remains. 


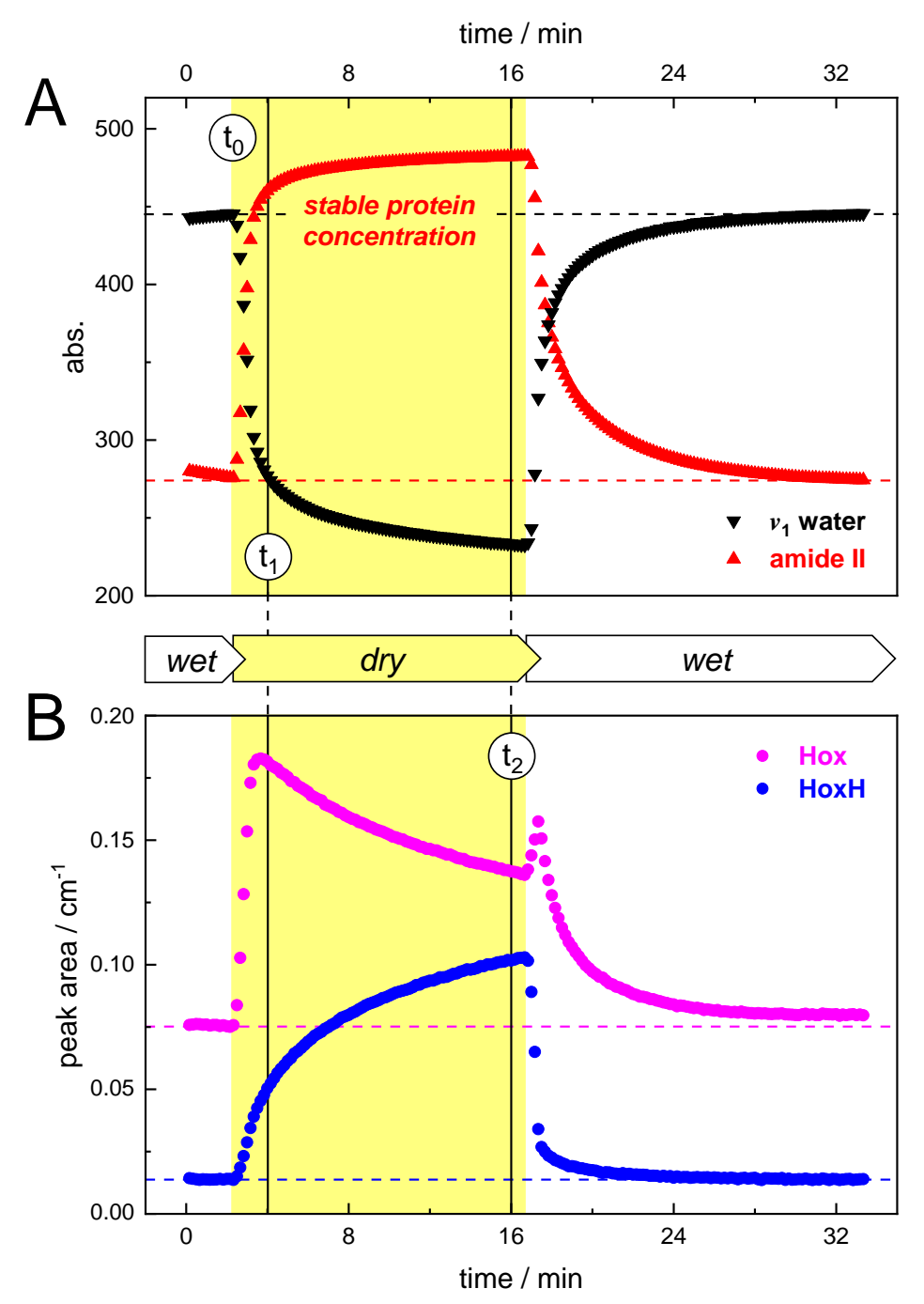

Figure 3. Kinetic evaluation of ATR FTIR data. (A) Plotting the $v_{1}$ and amide II band intensity over time highlights the changes in hydration and protein concentration when the 'wet' $\mathrm{N}_{2}$ aerosol is switched to 'dry' $\mathrm{N}_{2}$ gas at $\mathrm{t}_{0}$ (upper panel). Between $\mathrm{t}_{1}$ and $\mathrm{t}_{2}$, a relatively stable protein concentration is established before the system is switched back to 'wet' conditions. (B) Both Hox and HoxH increase with the protein concentration in the initial dehydration period between $\mathrm{t}_{0}$ and $\mathrm{t}_{1}$ while Hox slowly converts to HoxH in the dehydrated protein film. Note the reversibility of the Hox to HoxH transition upon rehydration of the protein film.

HoxH increases already between time points $t_{0}$ and $t_{1}$; however, the rapid increase of protein concentration after $t_{0}$ affects the Hox population more visibly as it represents the main H-cluster state at the beginning of the experiment. Between time points $t_{1}$ and $t_{2}(\Delta t=12 \mathrm{~min})$ the protein concentration was about constant (Fig. 3A), which facilitated a quantitative evaluation of the 
$\mathrm{CO} / \mathrm{CN}^{-}$band shifts of the H-cluster via IR difference spectra (Fig. 3B). Within the spectral resolution of our experiment, all band positions are identical to those of HoxH as formed in the presence of NaDT (Fig. S4 and Tab. S1). ${ }^{[14]}$ However, while near-complete state conversion was observed with $10 \mathrm{mM} \mathrm{NaDT}(>90 \%$ ) in earlier experiments, the HoxH yield was only 50\% when $10 \mathrm{mM}$ TCEP was used. As discussed Supporting Information, this is presumably due to the $\sim 250$ $\mathrm{mV}$ less reducing redox potential of TCEP at $\mathrm{pH} 4$ vs. NaDT. Following the dehydration protocol described above, the Hox to HoxH conversion was probed with samples containing 10 mM DTT or $10 \mathrm{mM}$ ascorbic acid, resulting in $35 \%$ or $20 \%$ enrichment of $\mathbf{H o x H}$, respectively (Fig. 4). In samples without reductant, only negligible HoxH was detected (Fig. S3). These results clearly emphasize the need for a reductant in HoxH formation and prove that NaDT is not required.

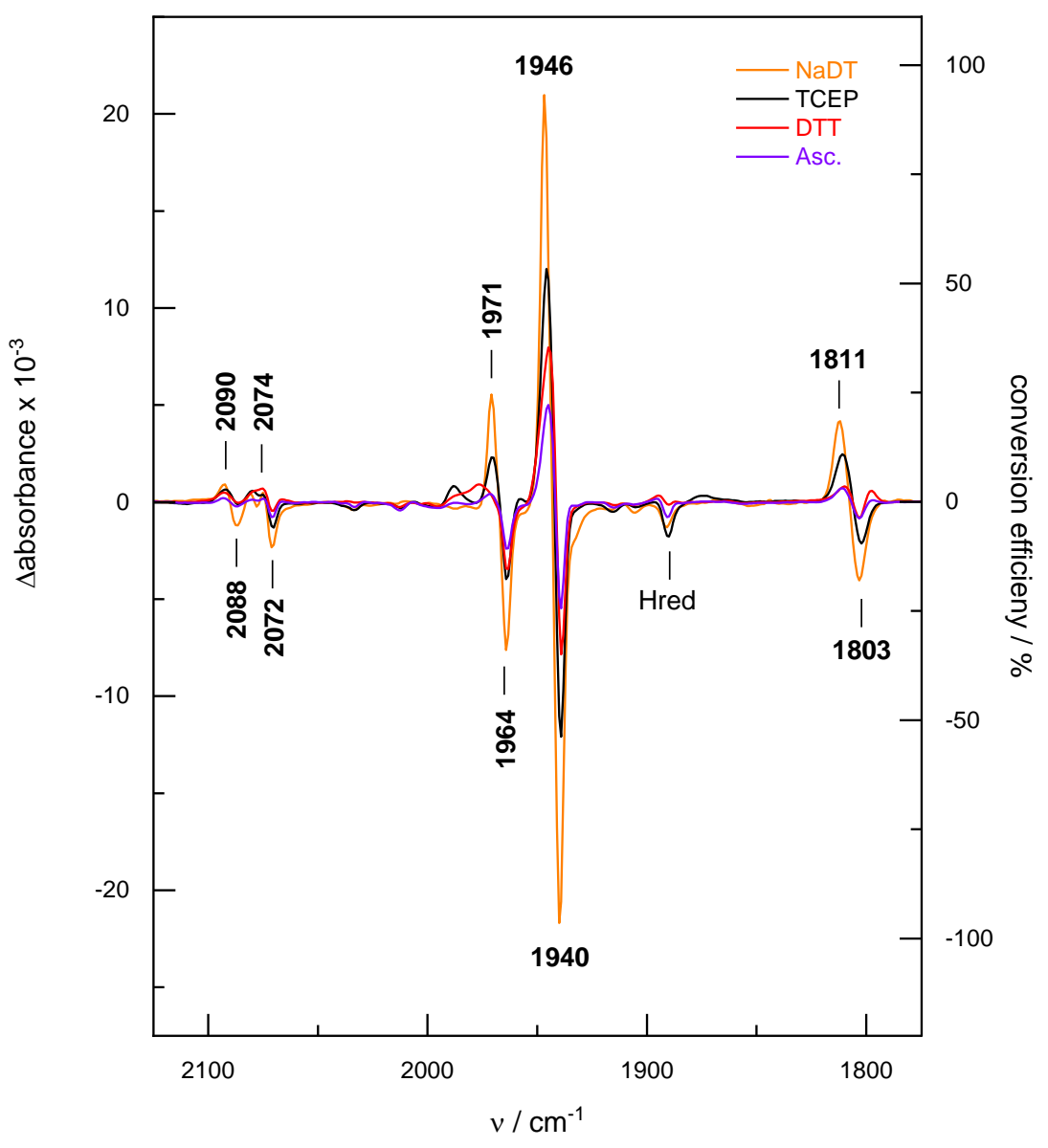

Figure 4. ATR FTIR difference spectra. Accumulation of HoxH (positive bands) over Hox (negative bands) over a time span of $12 \mathrm{~min}$ in partially dehydrated $\mathrm{CrHydA} 1$ protein films at $\mathrm{pH}$ 4 and in the presence of reductants TCEP (black), DTT (red), or ascorbic acid (violet). For reference, the $>90 \%$ conversion of Hox into HoxH in the presence of NaDT is shown (orange) that defines the conversion efficiency (right $\mathrm{X}$-axis). 
Although direct experimental proof for a protonated cysteine ligand is yet to obtain, the present findings reinforce our model for the accumulation of $\mathbf{H o x H}$ via a transiently reduced and protonated $[4 \mathrm{Fe}]_{\mathrm{H}}$ cluster (Fig. S5). ${ }^{[14,22]}$ After oxidation of the H-cluster due to proton reduction and $\mathrm{H}_{2}$ release, acidic conditions stabilize HoxH (proton 'backpressure') whereas Hox is regained under alkaline conditions. This model is supported by the low but significant $\mathrm{H}_{2}$ release activity of CrHydA1 in the presence of TCEP, DTT, or ascorbic acid (Fig. S6). Protonation of the [4Fe $]_{\mathrm{H}}$ cluster may advance via a regulatory proton pathway that is conserved among standard [FeFe]hydrogenases ${ }^{[14]}$ and differs from the catalytic proton pathway to the diiron site. ${ }^{[29,30]}$ This proton is therefore not part of the hydrogen turnover reaction but may impede a premature reduction and protonation of the diiron site. ${ }^{[31]}$

\section{CONCLUSIONS}

In summary, we demonstrated that HoxH formation does not require NaDT (or its decay products) but can be induced in the presence of mild reductants like TCEP, DTT, or ascorbic acid. The suggested nomenclature 'Hox-DT ${ }_{i}$ ' is inadequate. ${ }^{[26]}$ The accumulation of $\mathbf{H o x H}$ upon partial dehydration might be related to intermolecular electron transfer, the increase of reductant concentration, and a relative decrease in $\mathrm{pH}$ in the film. ${ }^{[14]}$ We speculate that solvent access to the $\mathrm{H}$-cluster is hampered in the dehydrated protein film so that proton release from the $[4 \mathrm{Fe}]_{\mathrm{H}}$ cluster is slowed down or even impaired. This effect then leads to accumulation of $\mathbf{H o x H}$ in the presence of mild reductants that drive the catalytic cycle at a lower rate than NaDT. Since protein film electrochemistry hinted at an inhibitory effect of $\mathrm{Na}_{2} \mathrm{SO}_{3}$ on $\mathrm{CrHydA} 1^{[26]}$, we will join Martini et al. in emphasizing that potentially 'non-innocent' reductants like NaDT should be used with great care in hydrogenase preparations and activity essays. The accumulation of a protonated [4Fe-4S] cluster under mildly reducing conditions now suggests that proton-coupled electron transfer involving a cysteine ligand may represent a general redox tuning mechanism. ${ }^{[31]}$ Similar concepts have been employed to explain the redox chemistry of ferredoxins, Rieske proteins, mitoNEET, and other metalloproteins. ${ }^{[32-35]}$ 


\section{ACKNOWLEDGMENTS}

The European Union's Horizon 2020 research and innovation program is gratefully acknowledged for funding to MS (Marie Skłodowska-Curie Grant No. 897555). JD is grateful for funding by the DFG (project no. 461338801). UPA acknowledges funding by the DFG (under Germanys' Excellence Strategy - EXC 2033-390677874) and the Fraunhofer Internal Programs (Grant No. ATTRACT 097- 602175). MH thanks UniSysCat (Cluster of Excellence Berlin) for financial support. STS is funded by the DFG within the framework of SPP 1927 priority program 'IronSulfur for Life' (Grant No. STR1554/5-1). We thank Petko Chernev (Universitet Uppsala, Sweden) for providing the IR curve fitting software 'GloGaussFit'.

\section{REFERENCES}

[1] W. Lubitz, H. Ogata, O. Rüdiger, E. Reijerse, Chem. Rev. 2014, 114, 4081-4148.

[2] V. Fourmond, E. S. Wiedner, W. J. Shaw, C. Léger, J. Am. Chem. Soc. 2019, 141, 1126911285.

[3] V. Fourmond, N. Plumeré, C. Léger, Nat. Rev. Chem. 2021, 5, 348-360.

[4] C. Madden, M. D. Vaughn, I. Díez-Pérez, K. A. Brown, P. W. King, D. Gust, A. L. Moore, T. A. Moore, J. Am. Chem. Soc. 2012, 134, 1577-1582.

[5] G. Goldet, C. Brandmayr, S. T. Stripp, T. Happe, C. Cavazza, J. C. Fontecilla-Camps, F. A. Armstrong, J. Am. Chem. Soc. 2009, 131, 14979-14989.

[6] H. Land, M. Senger, G. Berggren, S. T. Stripp, ACS Catal. 2020, 10, 7069-7086.

[7] J. T. Kleinhaus, F. Wittkamp, S. Yadav, D. Siegmund, U. P. Apfel, Chem. Soc. Rev. 2021, $50,1668-1784$.

[8] J. A. Birrell, P. Rodríguez-Maciá, E. J. Reijerse, M. A. Martini, W. Lubitz, Coord. Chem. Rev. 2021, 449, 214191.

[9] Y. Nicolet, C. Piras, P. Legrand, C. E. Hatchikian, J. C. Fontecilla-Camps, Structure 1999, 7, 13-23.

[10] M. Senger, S. Mebs, J. Duan, F. Wittkamp, U.-P. Apfel, J. Heberle, M. Haumann, S. T. Stripp, Proc. Natl. Acad. Sci. U. S. A. 2016, 113, 8454-8459.

[11] J. Esselborn, L. Kertess, U.-P. Apfel, E. Hofmann, T. Happe, J. Am. Chem. Soc. 2019, 141, 17721-17728.

[12] J. Esselborn, N. Muraki, K. Klein, V. Engelbrecht, N. Metzler-Nolte, U.-P. Apfel, E. 
Hofmann, G. Kurisu, T. Happe, Chem. Sci. 2016, 7, 959-968.

[13] W. Lubitz, E. Reijerse, M. van Gastel, Chem. Rev. 2007, 107, 4331-4365.

[14] M. Senger, S. Mebs, J. Duan, O. Shulenina, K. Laun, L. Kertess, F. Wittkamp, U.-P. Apfel, T. Happe, M. Winkler, M. Haumann, S. T. Stripp, Phys. Chem. Chem. Phys. 2018, $20,3128-3140$.

[15] S. T. Stripp, S. Mebs, M. Haumann, Inorg. Chem. 2020, 59, 16474-16488.

[16] K. Laun, I. Baranova, J. Duan, L. Kertess, F. Wittkamp, U.-P. Apfel, T. Happe, M. Senger, S. T. Stripp, Dalt. Trans. 2021, 50, 3641-3650.

[17] D. W. Mulder, M. W. Ratzloff, M. Bruschi, C. Greco, E. Koonce, J. W. Peters, P. W. King, J. Am. Chem. Soc. 2014, 136, 15394-15402.

[18] D. W. Mulder, Y. Guo, M. W. Ratzloff, P. W. King, J. Am. Chem. Soc. 2017, 139, 83-86.

[19] E. J. Reijerse, C. C. Pham, V. Pelmenschikov, R. Gilbert-Wilson, A. Adamska-Venkatesh, J. F. Siebel, L. B. Gee, Y. Yoda, K. Tamasaku, W. Lubitz, T. B. Rauchfuss, S. P. Cramer, J. Am. Chem. Soc. 2017, 139, 4306-4309.

[20] M. Winkler, M. Senger, J. Duan, J. Esselborn, F. Wittkamp, E. Hofmann, U.-P. Apfel, S. T. Stripp, T. Happe, Nat. Commun. 2017, 8, 16115.

[21] V. Pelmenschikov, J. A. Birrell, C. C. Pham, N. Mishra, H. Wang, C. Sommer, E. Reijerse, C. P. Richers, K. Tamasaku, Y. Yoda, T. B. Rauchfuss, W. Lubitz, S. P. Cramer, J. Am. Chem. Soc. 2017, 139, 16894-16902.

[22] M. Senger, K. Laun, F. Wittkamp, J. Duan, M. Haumann, T. Happe, M. Winkler, U.-P. Apfel, S. T. Stripp, Angew. Chemie Int. Ed. 2017, 56, 16503-16506.

[23] S. Mebs, J. Duan, F. Wittkamp, S. T. Stripp, T. Happe, U.-P. Apfel, M. Winkler, M. Haumann, Inorg. Chem. 2019, 58, 4000-4013.

[24] J. Duan, S. Mebs, K. Laun, F. Wittkamp, J. Heberle, E. Hofmann, U.-P. Apfel, M. Winkler, M. Senger, M. Haumann, S. T. Stripp, ACS Catal. 2019, 9, 9140-9149.

[25] P. Rodríguez-Maciá, N. Breuer, S. DeBeer, J. A. Birrell, ACS Catal. 2020, 10, 1308413095.

[26] M. A. Martini, O. Rüdiger, N. Breuer, B. Nöring, S. DeBeer, P. Rodríguez-Maciá, J. A. Birrell, J. Am. Chem. Soc. 2021, 143, 18159-18171.

[27] J. Esselborn, C. Lambertz, A. Adamska-Venkatesh, T. Simmons, G. Berggren, J. Noth, J. Siebel, A. Hemschemeier, V. Artero, E. Reijerse, M. Fontecave, W. Lubitz, T. Happe, Nat. Chem. Biol. 2013, 9, 607-609. 
[28] S. T. Stripp, ACS Catal. 2021, 11, 7845-7862.

[29] J. Duan, M. Senger, J. Esselborn, V. Engelbrecht, F. Wittkamp, U.-P. Apfel, E. Hofmann, S. T. Stripp, T. Happe, M. Winkler, Nat. Commun. 2018, 9, 4726.

[30] M. Senger, V. Eichmann, K. Laun, J. Duan, F. Wittkamp, G. Knör, U.-P. Apfel, T. Happe, M. Winkler, J. Heberle, S. T. Stripp, J. Am. Chem. Soc. 2019, 141, 17394-17403.

[31] M. Haumann, S. T. Stripp, Acc. Chem. Res. 2018, 51, 1755-1763.

[32] K. Chen, C. A. Bonagura, G. J. Tilley, J. P. McEvoy, Y.-S. Jung, F. A. Armstrong, C. D. Stout, B. K. Burgess, Nat. Struct. Biol. 2002, 9, 188-192.

[33] Y. Zu, M. M. J. Couture, D. R. J. Kolling, A. R. Crofts, L. D. Eltis, J. A. Fee, J. Hirst, Biochemistry 2003, 42, 12400-12408.

[34] J. A. Zuris, D. A. Halim, A. R. Conlan, E. C. Abresch, R. Nechushtai, M. L. Paddock, P. A. Jennings, J. Am. Chem. Soc. 2010, 132, 13120-13122.

[35] J. Liu, S. Chakraborty, P. Hosseinzadeh, Y. Yu, S. Tian, I. Petrik, A. Bhagi, Y. Lu, Chem. Rev. 2014, 114, 4366-4369. 
Supporting Information

\section{Contents}

\section{Supporting Methods}

Preparation of $\mathrm{CrHydA1}$ holoenzyme

In situ ATR FTIR spectroscopy

\section{Supporting Data}

Fig. S1. Reductants discussed in this study

Fig. S2. ATR FTIR absorbance spectra

Fig. S3. Reference ATR FTIR difference spectra

Fig. S4. Evaluation of the spectral signatures of Hox and HoxH

Fig. S5. Accumulation of HoxH

Fig. S6. Activity measurements

Tab. S1. Fit parameters of ATR FTIR spectra

Supporting References 
Preparation of $\boldsymbol{C r H y d A 1}$ holoenzyme. $C r H y d A 1$ apo-protein with a $C$-terminally fused streptagII was expressed and synthesized in E. coli strain BL21(DE3) $\Delta$ iscR under anaerobic conditions as described by Kuchenreuther and co-workers. ${ }^{[1]}$ At variance with this protocol, the [FeFe]hydrogenase-specific maturases HydEFG were not co-expressed, resulting in the production of inactive $C r$ HydA1 apo-protein. ${ }^{[2]}$ Protein purification was achieved by strep-tactin affinity chromatography under strictly anaerobic conditions with a $10 \mathrm{mM}$ Tris-HCl buffer $(\mathrm{pH} 8.0)$ and 2 $\mathrm{mM} \mathrm{NaDT}$ as described by von Abendroth and co-workers. ${ }^{[3]}$

The ADT complex $\left[\mathrm{FeFe}\left[\mathrm{m}-\left(\mathrm{SCH}_{2}\right)_{2} \mathrm{NH}\right](\mathrm{CN})_{2}(\mathrm{CO})_{4}\right]\left[\mathrm{Et}_{4} \mathrm{~N}\right]_{2}$ was synthesized and purified as described by Li and Rauchfuss. ${ }^{[4]}$ Maturation of $\mathrm{CrHydA} 1$ apo-protein with a tenfold excess of the ADT complex was achieved by incubation for $\sim 1 \mathrm{~h}$ at $24{ }^{\circ} \mathrm{C}$ in $100 \mathrm{mM}$ potassium phosphate buffer (pH 6.8) with $2 \mathrm{mM} \mathrm{NaDT}$ to ensure reducing conditions as described by Esselborn and coworkers. ${ }^{[5]}$ The activated $C r$ HydA1 holoenzyme was subsequently cleaned from residual ADT complex and NaDT by use of a NAPTM 5 (GE Healthcare) size exclusion chromatography and adjusted to $\mathrm{pH} 8$ in $10 \mathrm{mM}$ Tris- $\mathrm{HCl}$ buffer. In the absence of $\mathrm{H}_{2}$, no reduction of methyl viologen was observed, and no traces of $\mathbf{H o x H}$ were observed when the sample was adjusted to $\mathrm{pH} 4$. These data prove that the samples are completely NaDT-free. Enzyme preparations were concentrated to $\sim 1 \mathrm{mM}$ CrHydA1 ( 48 g/L) using Amicon Ultra centrifugal filters $30 \mathrm{~K}$ (Millipore) and stored at $-80{ }^{\circ} \mathrm{C}$ under strictly anaerobic conditions.

In situ ATR FTIR spectroscopy. The FTIR spectrometer (Tensor27, Bruker Optik, Germany) was equipped with a triple-reflection ZnSe/Si crystal ATR cell (Smith Detection, USA) and placed in an anaerobic chamber (Coy Laboratories, USA). Infrared spectra were recorded with $80 \mathrm{kHz}$ scanning velocity at a spectral resolution of $2 \mathrm{~cm}^{-1}$. Under these conditions, the time-resolution of data acquisition is in the range of $1 \mathrm{~s}$ (one interferometer scan in the forward/backward direction).

To prepare a protein film, $1 \mu \mathrm{L} \mathrm{CrHydA1} \mathrm{solution}(\sim 1 \mathrm{mM})$ was pipetted onto the silicon crystal of the ATR cell and enclosed by a custom-made gas titration cell ${ }^{[6]}$ to concentrate the sample under a stream of dry $\mathrm{N}_{2}$ gas. Once $\sim 60 \%$ of water was removed from the protein solution, a relatively dry protein film was formed. Then, the gas was sent through a reservoir of $150 \mathrm{~mL}$ aqueous buffer, creating a 'wet' aerosol that was used to rehydrate the hygroscopic protein film. Changing between dry gas and wet aerosol, the humidity of the protein film can be controlled. Further details of the experimental setup can be found in reference ${ }^{[6]}$. 
A

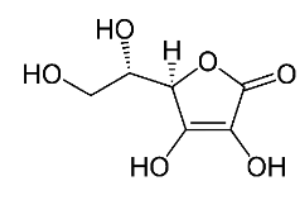

B

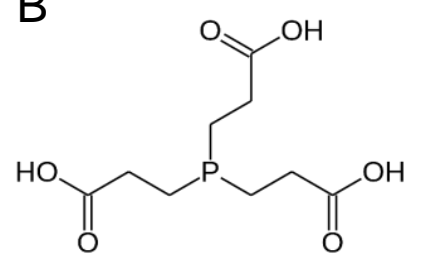

C<smiles>OC(CS)C(O)CS</smiles>

D

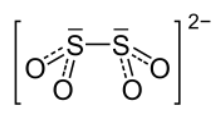

Figure S1. Reductants discussed in this study. (A) Ascorbic acid ('Vitamin C', $\mathrm{E}^{0}=-80 \mathrm{mV}$ vs. SHE). (B) Tris(2-carboxyethyl)phosphine (TCEP, $\mathrm{E}^{0}=-290 \mathrm{mV}$ vs. SHE). (C) Dithiothreitol (DTT, $\mathrm{E}^{0}=-330 \mathrm{mV}$ vs. SHE). Based on literature reports, a redox potential of $-240 \mathrm{mV},-200 \mathrm{mV}$, or $-160 \mathrm{mV}$ for DTT, TCEP, or ascorbic acid is assumed at $\mathrm{pH} 4 .^{[7-9]}$ (D) Sodium dithionite $\left(\mathrm{Na}_{2} \mathrm{~S}_{2} \mathrm{O}_{4}\right)$ has a standard potential of $\mathrm{E}^{0}=-660 \mathrm{mV}$ vs. SHE (approximately $-450 \mathrm{mV}$ at $\left.\mathrm{pH} 4\right){ }^{[10]}$ 

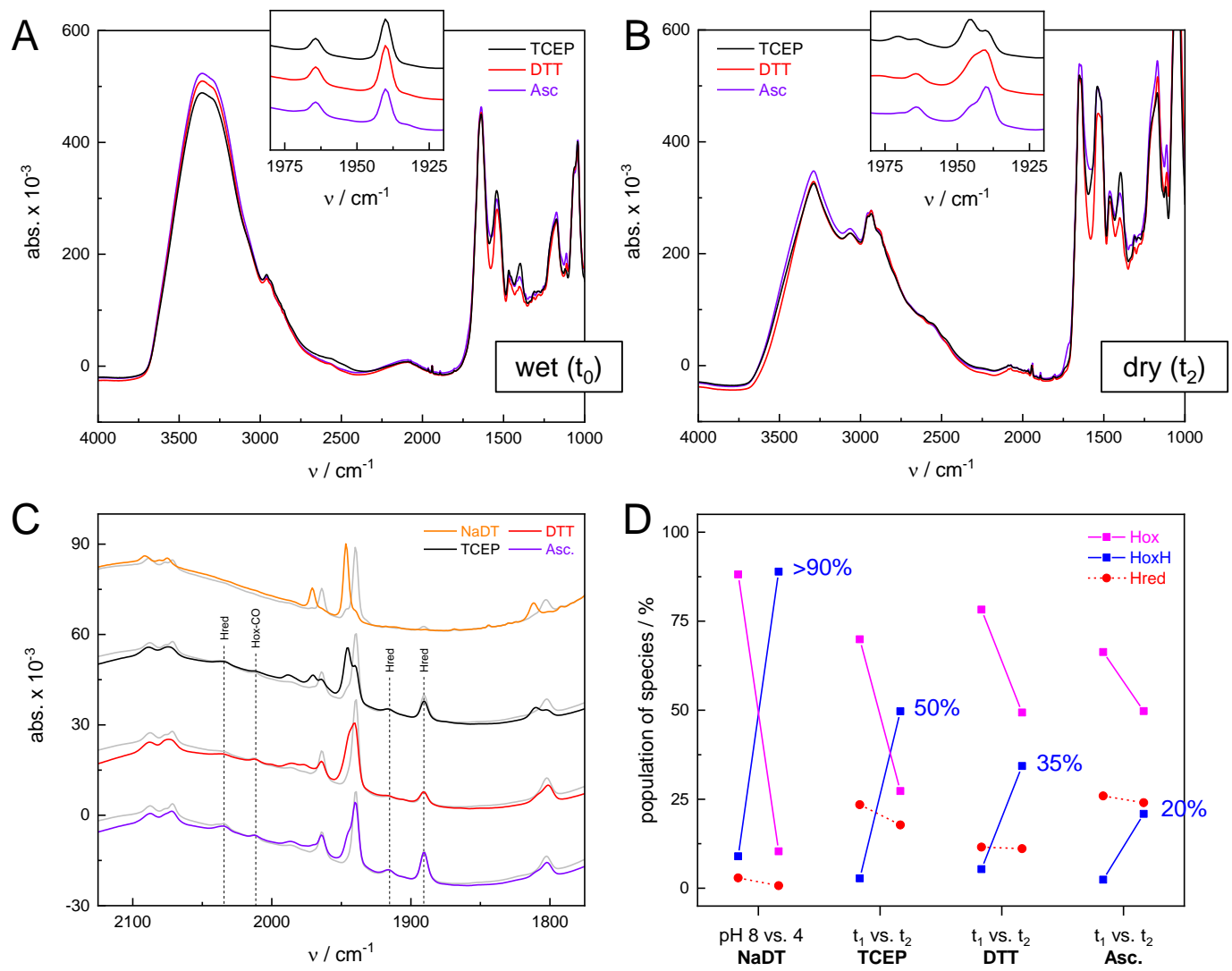

Figure S2. ATR FTIR absorbance spectra. Absorbance spectra of (A) fully hydrated ('wet' = $\left.\mathrm{t}_{0}\right)$ and (B) partially dehydrated protein films ('dry' $=\mathrm{t}_{2}$ ) of CrHydA1 samples with $10 \mathrm{mM}$ TCEP, DTT, or ascorbic acid at $\mathrm{pH} 4$. The 'dry' film contains $\sim 50 \%$ liquid water relative to fully hydrated conditions, based on the intensity of the $\mathrm{OH}$ band of liquid water at $3360 \mathrm{~cm}^{-1}$ as plotted in Figure 2B of the main text. The inset in panel (A) and (B) shows a representative section of the COvibrational frequency range of the H-cluster, highlighting the changes in the Hox and HoxH populations. Upon dehydration, which causes an increase of the protein and reductant concentration in the film and may decrease the $\mathrm{pH}^{[11]}$, HoxH is accumulated at the expense of Hox. Spectra in (A) were recorded after 1-2 h under a 'wet' $\mathrm{N}_{2}$ aerosol. Note the lack of HoxH under these conditions. (C) Full $\mathrm{CO} / \mathrm{CN}^{-}$frequency regime of the $\mathrm{H}$-cluster, comparing the spectra at $\mathrm{t}_{1}$ (grey traces) and $t_{2}$ (colored traces) for different reductants. Sample dehydration was started at $t_{0}$, resulting in larger changes in protein concentration (see Figure $2 \mathrm{~B}$ in the main text). Between time points $t_{1}$ and $t_{2}$, however, the protein concentration was about constant, so these spectra were used to calculate the difference spectra of Figure 3 in the main text. Residual H-cluster species in the Hred and Hox-CO state are annotated. For comparison, spectra in the presence of $10 \mathrm{mM} \mathrm{NaDT}$ at $\mathrm{pH} 8$ (grey) and $\mathrm{pH} 4$ (orange) are shown. ${ }^{[11]}$ (D) Quantitative evaluation of the state populations for Hox, HoxH, and Hred at $t_{1}$ and $t_{2}$ (time points as defined in Figure $2 B$ in the main text). All reductants facilitate significant Hox to HoxH conversion, with TCEP and DTT being more effective (50\% and $35 \%$ HoxH) than ascorbic acid (20\% HoxH). In the presence of NaDT, more than $90 \%$ HoxH is accumulated when switched from $\mathrm{pH} 8$ to $\mathrm{pH} 4$ in situ. ${ }^{[1]}$ 

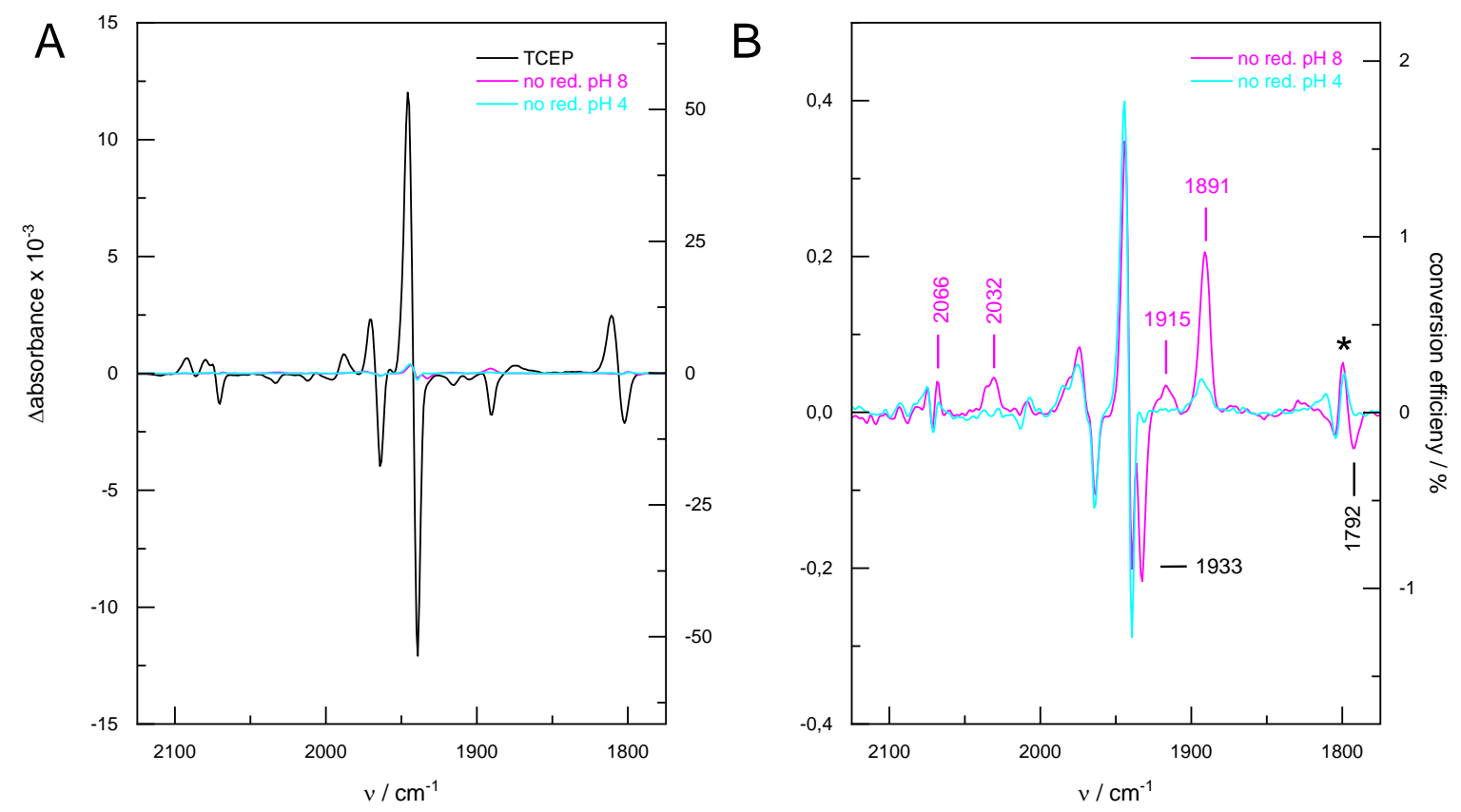

Figure S3. Reference ATR FTIR difference spectra. (A) When reductants were completely absent in $\mathrm{CrHydA1}$ preparations at $\mathrm{pH} 8$ or $\mathrm{pH} 4$, less than $2 \%$ Hox to HoxH conversion was observed upon partial dehydration (compare conversion efficiency axis in (B)). The difference spectrum of the sample with TCEP is plotted for comparison. (B) A close-up reveals a band at 1800 $\mathrm{cm}^{-1}(*)$, which presumably is due to a small population of $\mathbf{H r e d}^{\prime} \mathbf{H}$ at both $\mathrm{pH}$ values. ${ }^{[12]}$ Moreover, the $\mathrm{pH} 8$ sample shows a conversion of Hred' (bands at 1933 and $1792 \mathrm{~cm}^{-1}$ ) to Hred (bands at 2066, 2032, 1915, and $1891 \mathrm{~cm}^{-1}$ ) that is not observed in any $\mathrm{pH} 4$ preparation. This is expected because acidic conditions suppress Hred' and favor accumulation of Hred and Hsred. ${ }^{[13]}$ 

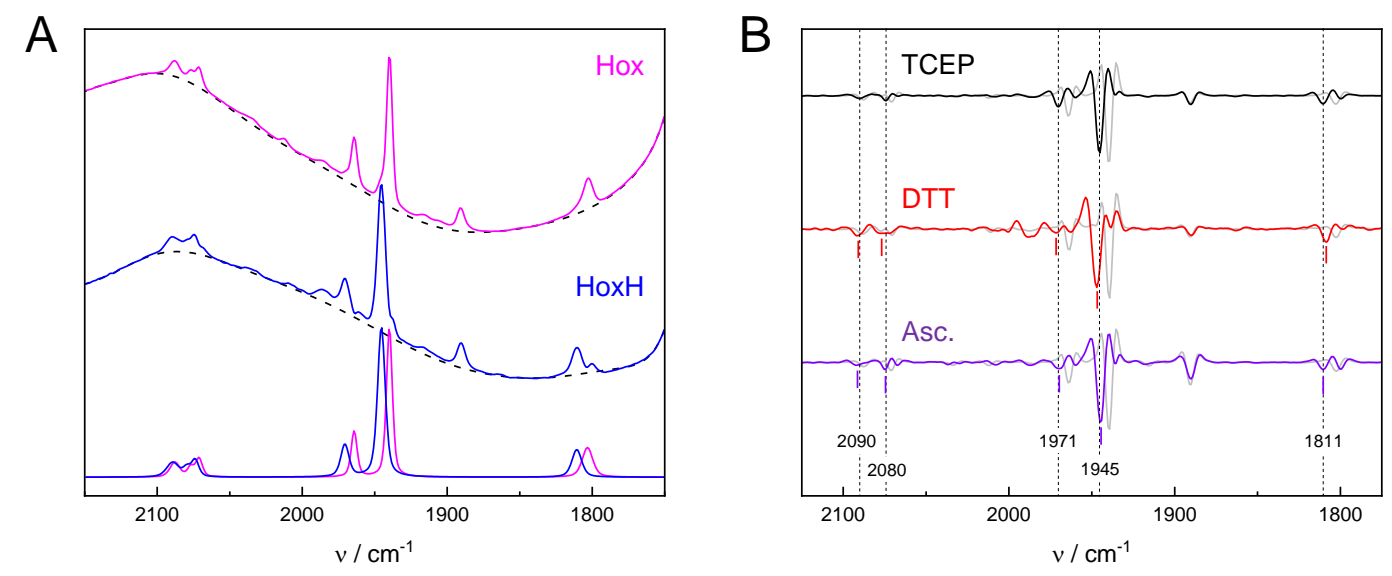

Figure S4. Evaluation of the spectral signatures of Hox and HoxH. (A) Partial subtraction of the FTIR absorbance spectra of the sample with TCEP at $t_{1}$ and $t_{2}$ (see Figure 2 in the main text) facilitated the generation of practically pure spectra for Hox (magenta) and HoxH (blue). Raw spectra were fitted with a polynomial baseline (dashed traces) and five Voigt profiles of defined frequency, full-width-at-half-maximum (fwhm), and intensity ratio (see Table S1). In-house software was used for the fitting procedure, as reported earlier. ${ }^{[11]}$ The fitted spectra are shown at the bottom of panel (A). (B) Second derivative analysis of the pure spectra of Hox and HoxH as observed in the presence of TCEP, DTT, or ascorbic acid supports the IR band positions as suggested by the fit results (Table S1). The small HoxH band shifts are in the range of the spectral resolution of the experiment $\left(2 \mathrm{~cm}^{-1}\right.$, see Supporting Methods). 


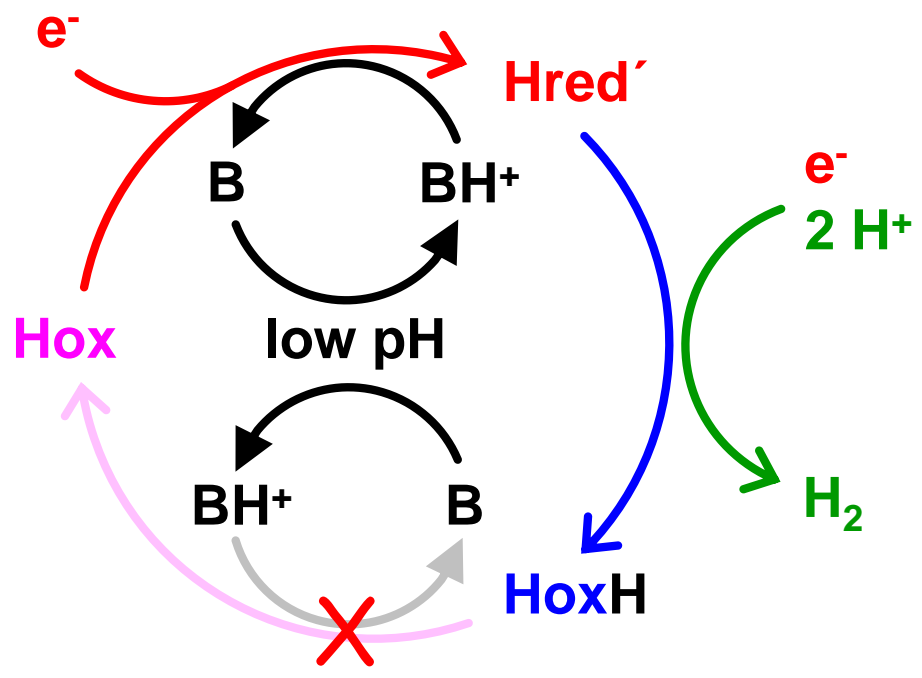

Figure S5. Accumulation of HoxH. The oxidized state Hox is converted into a state resembling Hred' by one-electron reduction of the $[4 \mathrm{Fe}-4 \mathrm{~S}]$ cluster and protonation of a cysteine ligand via an adjacent base (B, presumably a water molecule). ${ }^{[1-13]}$ Reducing equivalents ( $\mathrm{e}^{-}$) may stem from NaDT, TCEP, DTT, or ascorbic acid. In a second PCET step, a proton is reduced to a terminal hydride ligand at $\mathrm{Fe}_{\mathrm{d}}$ of the diiron site (resembling Hhyd, not shown in the scheme), which reacts with another proton to form $\mathrm{H}_{2}$ gas. At high $\mathrm{pH}, \mathbf{H o x}$ is recovered via deprotonation of the [4Fe$4 \mathrm{~S}$ ] cluster and re-protonation of the adjacent base. The scheme depicts the situation at low $\mathrm{pH}$. Here, HoxH accumulates when the base is protonated $\left(\mathrm{BH}^{+}\right)$and regain of $\mathbf{H o x}$ is impaired.

Table S1. Fit parameters of ATR FTIR spectra.

\begin{tabular}{cccc}
\hline state & $\boldsymbol{v} / \mathbf{c m}^{-\mathbf{1}}$ & fwhm $/ \mathbf{c m}^{-\mathbf{1}}$ & rel. amplitude \\
\hline Hox & 1803.2 & 8.6 & 0.35 \\
Hox & 1939.9 & 4.8 & 1.00 \\
Hox & 1964.2 & 4.9 & 0.31 \\
Hox & 2071.2 & 5.5 & 0.14 \\
Hox & 2087.9 & 8.0 & 0.16 \\
HoxH & 1810.6 & 8.0 & 0.23 \\
HoxH & 1945.4 & 6.3 & 1.00 \\
HoxH & 1970.6 & 6.7 & 0.23 \\
HoxH & 2079.6 & 6.0 & 0.05 \\
HoxH & 2089.4 & 10.0 & 0.15
\end{tabular}




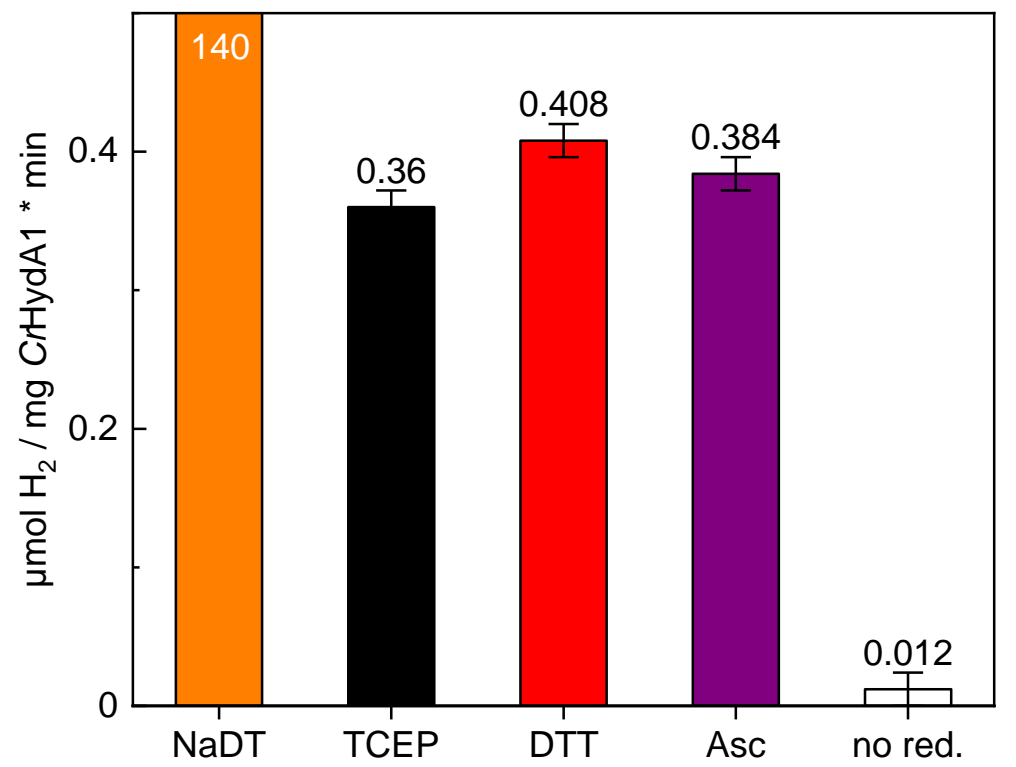

Figure S6. Activity measurements. In vitro $\mathrm{H}_{2}$ release activity was determined for various reductants. Specifically, $35 \mathrm{nmol} \mathrm{CrHydA1}$ was mixed with phosphate buffer (100 mM, pH 7) inside the glovebox with humid $\mathrm{Ar}$ atmosphere (total reaction volume $800 \mu \mathrm{L}$ ). Then hydrogenase samples in buffer were loaded to $37^{\circ} \mathrm{C}$ water bath for $10 \mathrm{~min}$. Meanwhile, reductants were purged with argon for $20 \mathrm{~min}$. After incubation of hydrogenase samples in the bath, $100 \mu \mathrm{L}$ of $890 \mathrm{mM}$ reductant stock solution was injected with the Hamiltonian syringe (resulting in $\sim 100 \mathrm{mM} \mathrm{NaDT}$, TCEP, DTT, or ascorbic acid). A reference sample was prepared with no reductant at all. Samples with $\mathrm{CrHydA} 1$ and reductants were incubated in a $37^{\circ} \mathrm{C}$ water bath for another $15 \mathrm{~min}$. Finally, $100 \mu \mathrm{L}$ of the gas phase (total headspace volume $\sim 8.1 \mathrm{~mL}$ ) was analyzed for $\mathrm{H}_{2}$ by gas chromatography as reported earlier. ${ }^{[3]}$ We detected 3500, 9.0, 10.2, 9.6, and $0.3 \mathrm{nmol} \mathrm{H}_{2}$, which

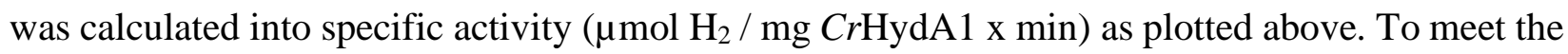
conditions in the FTIR experiment, methyl viologen (MV) was not used in the activity assays, which explains why the $\mathrm{H}_{2}$ release activity with $\mathrm{NaDT}$ is less than $10 \%$ of the values reported for activity assays with $\mathrm{MV} \cdot{ }^{[5]}$ 


\section{Supporting References}

[1] J. M. Kuchenreuther, C. S. Grady-Smith, A. S. Bingham, S. J. George, S. P. Cramer, J. R. Swartz, PLoS One 2010, 5, e15491.

[2] D. W. Mulder, D. O. Ortillo, D. J. Gardenghi, A. V. Naumov, S. S. Ruebush, R. K. Szilagyi, B. Huynh, J. B. Broderick, J. W. Peters, Biochemistry 2009, 48, 6240-6248.

[3] G. von Abendroth, S. T. Stripp, A. Silakov, C. Croux, P. Soucaille, L. Girbal, T. Happe, Int. J. Hydrogen Energy 2008, 33, 6076-6081.

[4] H. Li, T. B. Rauchfuss, J. Am. Chem. Soc. 2002, 124, 726-727.

[5] J. Esselborn, C. Lambertz, A. Adamska-Venkatesh, T. Simmons, G. Berggren, J. Noth, J. Siebel, A. Hemschemeier, V. Artero, E. Reijerse, M. Fontecave, W. Lubitz, T. Happe, Nat. Chem. Biol. 2013, 9, 607-609.

[6] S. T. Stripp, ACS Catal. 2021, 11, 7845-7862.

[7] I. B. Santarino, S. C. B. Oliveira, A. M. Oliveira-Brett, Electrochem. commun. 2012, 23, 114-117.

[8] L. Peng, X. Xu, M. Guo, X. Yan, S. Wang, S. Gao, S. Zhu, Metallomics 2013, 5, 920-927.

[9] H. Borsook, G. Keighley, Proc. Natl. Acad. Sci. 1933, 19, 875-878.

[10] S. G. Mayhew, Eur. J. Biochem. 1978, 85, 535-547.

[11] M. Senger, S. Mebs, J. Duan, O. Shulenina, K. Laun, L. Kertess, F. Wittkamp, U.-P. Apfel, T. Happe, M. Winkler, M. Haumann, S. T. Stripp, Phys. Chem. Chem. Phys. 2018, $20,3128-3140$.

[12] M. Senger, K. Laun, F. Wittkamp, J. Duan, M. Haumann, T. Happe, M. Winkler, U.-P. Apfel, S. T. Stripp, Angew. Chemie Int. Ed. 2017, 56, 16503-16506.

[13] K. Laun, I. Baranova, J. Duan, L. Kertess, F. Wittkamp, U.-P. Apfel, T. Happe, M. Senger, S. T. Stripp, Dalt. Trans. 2021, 50, 3641-3650. 